\title{
Propidium Monoazide Improves Quantification of Resting Spores of Plasmodiophora brassicae with qPCR
}

Fadi Al-Daoud, Department of Plant Agriculture, University of Guelph, Guelph, ON, N1G 2W1, Canada; Bruce D. Gossen, Agriculture and Agri-Food Canada, Saskatoon Research and Development Centre, Saskatoon, SK, S7N 0X2, Canada; and Justin Robson and Mary Ruth McDonald, Department of Plant Agriculture, University of Guelph

\begin{abstract}
Plasmodiophora brassicae, which causes clubroot of Brassica crops, persists in soil as long-lived resting spores. Quantitative polymerase chain reaction (qPCR) analysis is often used to quantify resting spores but does not distinguish between DNA of viable and nonviable spores. The impact of pretreating spores with propidium monoazide (PMA), which inhibits amplification of DNA from nonviable microorganisms, was assessed in several experiments. Spore suspensions from immature and mature clubs were heat treated; then, PMA-PCR analyses and bioassays were performed to assess spore viability. Prior to heat treatment, assessments comparing PMA-PCR to qPCR for mature spores were similar, indicating that most

of these spores were viable. However, only a small proportion $(<26 \%)$ of immature spores were amplified in PMA-PCR. Bioassays demonstrated that clubroot severity was much higher in plants inoculated with mature spores than with immature spores. Heat treatment produced little or no change in estimates of mature spores from qPCR but spore estimates from PMA-PCR and clubroot severity in bioassays were both substantially reduced. Estimates of spore concentration with PMA-PCR were less consistent for immature spores. To facilitate use of PMA-PCR on infested soil, a protocol for extracting spores from soil was developed that provided higher extraction efficiency than the standard methods.
\end{abstract}

Clubroot disease is caused by the obligate biotroph Plasmodiophora brassicae Woronin. It affects canola (Brassica napus L.) and other Brassica crops worldwide (Dixon 2009). The resting spores of $P$. brassicae survive in soil for many years (Peng et al. 2015). Resting spores germinate in response to root exudates, releasing primary zoospores that infect root hairs. Secondary zoospores develop, are released, and infect the root cortex cells. Infected roots undergo hyperplasia and hypertrophy to form the gall-like structures called clubs (Ingram and Tommerup 1972). Plants with severe clubroot are stunted and ripen prematurely due to restriction of water and nutrient uptake by infected roots, which can cause up to $100 \%$ yield loss in heavily infested canola fields (Hwang et al. 2011; Strelkov et al. 2007a, b).

Resting spores undergo a maturation process during the final stages of clubroot development in roots. Several studies have compared the structure of immature and mature resting spores (Ikegami et al. 1978; Kageyama and Asano 2009), and examined gene expression during resting spore formation and maturation (Ando et al. 2006; Feng et al. 2010; Siemens et al. 2009; Wu et al. 2012).

Integrated pest management strategies are being developed to augment and sustain genetic resistance in canola (Gossen et al. 2013; Hwang et al. 2014; Peng et al. 2015). The efficacy of soil treatments has been assessed by estimating resting spore concentration in the soil (Hwang et al. 2011; Peng et al. 2015). Recently, quantitative polymerase chain reaction (qPCR) has become the standard methodology for estimating spore load in soil. These estimates are occasionally supplemented with bioassays of clubroot severity (Ahmed et al. 2011; Peng et al. 2013) and use of vital stains such as Evan's blue to assess spore viability (Rennie et al. 2011; Tanaka et al. 1999). Bioassays and vital staining are required because qPCR amplifies DNA from both viable and nonviable spores. Bioassays can be resource intensive because they require up to 6 weeks for clubroot symptoms to develop, and there are strong indications that staining with Evan's blue is not a reliable indicator of spore viability for this pathogen (B. D. Gossen, unpublished).

Corresponding author: B. D. Gossen; E-mail: bruce.gossen@agr.gc.ca

Accepted for publication 25 October 2016.

() Her Majesty the Queen in Right of Canada, as represented by the Minister of Agriculture and Agri-Food Canada
A number of methods have been developed to exclude nonviable spores from amplification in qPCR (Fittipaldi et al. 2012). Most of these methods involve treating cells with chemicals that penetrate nonviable cells but not viable cells. These chemicals bind to the DNA in nonviable cells and inhibit amplification. One of the most effective chemicals is propidium monoazide (PMA), which penetrates the cell membrane of nonviable cells of bacteria and fungi, binds to DNA when photoactivated, and inhibits qPCR amplification of nonviable cells (Agustí et al. 2013; Andorrà et al. 2010; Moyne et al. 2013; Rawsthorne et al. 2009; Vesper et al. 2008; Wang et al. 2014).

The main objective of the current project was to determine whether PMA-PCR could be used to develop accurate and reliable estimates of the concentration of viable resting spores of $P$. brassicae. The second objective was to determine whether PMA-PCR could distinguish between mature and immature resting spores, because differences in cell wall structures that may affect permeability have been reported (Ikegami et al. 1978; Kageyama and Asano 2009). A third objective was to develop an improved protocol for extracting resting spores from soil for use with PMA-PCR.

\section{Materials and Methods}

Plants and soil. Samples of clubbed roots of a susceptible canola breeding line (B. napus line ACS-N39; Agriculture and Agri-Food Canada) and naturally infested muck soil (hemic histosol, approximately $79 \%$ organic matter, $\mathrm{pH} 6.4$ ) were collected in 2014 from a field at the Muck Crops Research Station of the University of Guelph at Bradford, ON, Canada. The site is infested with pathotype 6 of $P$. brassicae (S. Strelkov, personal communication). Resting spores designated as "immature" were extracted from the clubbed roots of plants harvested at 6 weeks after seeding and those designated as "mature" were from 9-week-old plants. Clubs were stored at $-20^{\circ} \mathrm{C}$ and soil samples were dried at room temperature (approximately $23^{\circ} \mathrm{C}$ ) or $30^{\circ} \mathrm{C}$ and stored at room temperature until use. Resting spores were extracted from clubbed roots using the method of Strelkov et al. (2007b). Briefly, 3 to $6 \mathrm{~g}$ of frozen clubbed roots was thawed in sterile deionized water $\left(\mathrm{sdH}_{2} \mathrm{O}\right)$ for approximately $20 \mathrm{~min}$. An electric blender was used to macerate the tissue in $100 \mathrm{ml}$ of $\mathrm{sdH}_{2} \mathrm{O}$ for $2 \mathrm{~min}$, and the suspension was then filtered through eight layers of cheesecloth. The suspension was diluted 10-fold prior to resting spore quantification with a hemocytometer.

PMA treatment, DNA extraction, and qPCR. Resting spore suspensions were treated with PMA (Biotium) in a 0.1-ml final 
volume in clear 2-ml conical tubes (Fisher Scientific). Three biological replicates were treated for each PMA concentration. Additional control samples that did not undergo the PMA treatment protocol were included to represent the qPCR protocol. After addition of the PMA to the samples, or water to the controls, the tubes were shaken in the dark at room temperature (approximately $23^{\circ} \mathrm{C}$ ) in an orbital shaker at $300 \mathrm{rpm}$ for $30 \mathrm{~min}$. The tubes were then put on ice and exposed to a 500-W halogen light (Globe Electric Company) $20 \mathrm{~cm}$ away for 15 min to activate the PMA. Finally, the tubes were flash frozen in liquid nitrogen and stored at $-80^{\circ} \mathrm{C}$ prior to DNA extraction.

All DNA extractions were performed using the PowerSoil DNA Extraction Kit (Mo Bio Laboratories) as recommended by the manufacturer. Approximately $0.1 \mathrm{~g}$ of muck soil or $0.1 \mathrm{ml}$ of spore suspension was used for DNA extraction. All qPCR analyses were performed using a multiplexed TaqMan assay that included a competitive internal positive control (CIPC) (Deora et al. 2015), with a slight modification. The internal control DNA was added at a concentration of $10^{-8}$ to $10^{-9}$ ng $\mu \mathrm{l}^{-1}$ that had a quantification cycle $\left(\mathrm{C}_{\mathrm{q}}\right)$ of 28 to 32 in the notemplate control. When inhibition was detected in a qPCR assay (when the $\mathrm{C}_{\mathrm{q}}$ of the CIPC of the sample rose above the CIPC of the negative control), estimates were adjusted (Deora et al. 2015). Samples with high levels of inhibition $\left(\Delta \mathrm{C}_{\mathrm{q}} \geq 3.3\right)$ were diluted 10 times and assayed again to produce a lower $\Delta \mathrm{C}_{\mathrm{q}}$ value. This ensured that all adjustments were less than 10 -fold. For a sample with moderate inhibition $\left(\Delta \mathrm{C}_{\mathrm{q}} \leq\right.$ 3.2 ), the following formula was used to adjust the estimate (Bilodeau 2011): concentration $=$ the estimated concentration based on the standard curve $\times(E+1)^{\Delta \mathrm{Cq}}$, where $\mathrm{E}=$ efficiency and $\Delta \mathrm{C}_{\mathrm{q}}=\mathrm{C}_{\mathrm{q}}$ sample $\mathrm{C}_{\mathrm{q}}$ control (water). A standard curve that represented $10^{3}$ to $10^{7}$ spores/ reaction was included with each qPCR analysis. All qPCR reactions had efficiencies between 90 and $110 \%$ and $R^{2}>0.99$, as calculated from the standard curves. Technical duplicates were analyzed for each of the biological triplicates.

Interaction of PMA and heat exposure. The study consisted of four experiments: one experiment with mature resting spores, one experiment with immature spores, and two experiments comparing both mature and immature spores. In each experiment, resting spore suspensions were exposed to $80^{\circ} \mathrm{C}$ for varying lengths of time to reduce the viability of a portion of the resting spores, then treated with PMA to prevent amplification of DNA from nonviable spores. Large volumes $(250 \mathrm{ml})$ were used in some experiments to allow for bioassays to be performed on the same spore suspensions used for the PMA-PCR analyses, and small volumes $(0.1 \mathrm{ml})$ were used in other experiments to maximize the uniformity of temperature exposure. A previous study had used a heat treatment to reduce the viability of resting spores (Donald et al. 2002).

Mature resting spores experiment, large volume. In a study of mature resting spores alone, a large volume $(250 \mathrm{ml})$ of spore suspension in a large glass beaker was placed in a drying oven at $80^{\circ} \mathrm{C}$ for 0,30 or $60 \mathrm{~min}$, with one beaker per treatment. The suspension contained a relatively low concentration of spores $\left(8 \times 10^{5}\right.$ spores $\mathrm{ml}^{-1}$ ). Three subsamples of each spore suspension were included in each PMA treatment to produce a final concentration of 0,40 , 80 , or $120 \mu \mathrm{M}$ PMA in $0.1 \mathrm{ml}$ of final volume. The PMA was then photoactivated as described above.

Immature resting spores experiment, small volume. This experiment assessed small volumes $(0.1 \mathrm{ml}$ in $1.5-\mathrm{ml}$ tubes $)$ of high concentrations $\left(5 \times 10^{7}\right.$ spores $\left.\mathrm{ml}^{-1}\right)$ of immature resting spores treated at $80^{\circ} \mathrm{C}$ in a heat block for 0,5 , and $10 \mathrm{~min}$. There were three replicates per PMA treatment $(0,40,80$, or $120 \mu \mathrm{M}$ PMA) for each heat treatment.

Mature and immature resting spores experiments, large and small volumes. Two experiments compared mature and immature resting spores. One large-volume experiment was conducted with mature and immature resting spores at a moderate concentration $\left(8 \times 10^{6}\right.$ spores $\mathrm{ml}^{-1}$ ), in a similar manner to what was described above for the large-volume mature resting spore experiment. A small-volume experiment was conducted to assess high concentrations of mature $\left(4.4 \times 10^{10}\right.$ spores $\left.\mathrm{ml}^{-1}\right)$ and immature $\left(4.6 \times 10^{9}\right.$ spores $\left.\mathrm{ml}^{-1}\right)$ spores, in a similar manner to what was described above for the smallvolume immature resting spore experiment but with only 0 and $80 \mu \mathrm{M}$ PMA.
Bioassays. For the large-volume mature resting spore experiment and large-volume mature and immature resting spore experiment, bioassays were conducted on the susceptible canola line ACS N39 to assess the impact of heat treatments on clubroot severity at harvest. The small-volume studies could not be assessed because the number of treated spores was not sufficient for replicated bioassays. Each bioassay was set up in a randomized complete block design with four replicates and up to 10 plants per replicate. Canola was seeded in 19cm-tall plastic pots (cone-tainers; Stuewe and Sons Inc.) containing LA4 Sunshine Mix (Sun Gro Horticulture) that was saturated with a fertilizer solution containing $0.1 \%$ nitrogen, phosphate, potassium (20-20-20; Plant Products), and magnesium sulfate $(\mathrm{K}+\mathrm{S}$; Kali $\mathrm{GmbH})$. Two seeds were planted in each pot and thinned to one after emergence. Plants were grown in a growth room with a 16-h photoperiod at 25 and $20^{\circ} \mathrm{C}$ (day and night, respectively) and approximately $50 \%$ relative humidity. To promote clubroot development, plants were watered daily with a $\mathrm{dH}_{2} \mathrm{O}$-white vinegar $(5 \%$ acetic acid) solution with a $\mathrm{pH}$ of 6.0 , and fertilized weekly. Plants were inoculated at the base of the plant with $5 \mathrm{ml}$ of resting spore suspension within 1 week of planting. Clubroot symptoms were assessed at 6 weeks post-inoculation. Clubroot incidence (CI) was calculated as a proportion (percentage) of plants with clubroot symptoms. Clubroot severity was assessed using a 0-to-3 scale to separate clubs into severity classes. A disease severity index (DSI) was calculated using the following equation (Crête et al. 1963; Strelkov et al. 2006):

$\operatorname{DSI}(\%)=\frac{\sum[(\text { class number })(\text { number of plants in each class })]}{(\text { total number of plants per sample })(\text { number of classes }-1)} \times 100 \%$

In addition, two bioassays with 10 plants per treatment with no replicates in one experiment and four replicates in the other experiment were conducted at an inoculum concentration of $5 \mathrm{ml}$ of $1 \times 10^{6}$ spores $\mathrm{ml}^{-1}$ to assess nontreated immature and mature resting spores.

Staining with Evan's blue. For the experiment that assessed large volumes of mature and immature resting spores, subsamples of the suspensions were stained with Evan's blue (Sigma-Aldrich) using a standard method (Tanaka et al. 1999). Briefly, $0.1 \mathrm{ml}$ of resting spore suspension was mixed with an equal volume of $2 \%$ Evan's blue solution for $30 \mathrm{~min}$ at room temperature (approximately $23^{\circ} \mathrm{C}$ ). The stained spores were diluted fourfold with $\mathrm{sdH}_{2} \mathrm{O}$ and quantified with a hemocytometer. One hundred spores were counted for each sample and rated as viable (light-blue cytoplasm) or nonviable (dark-blue cytoplasm). Resting spore extraction, heat treatments, bioassay inoculations, PMA treatments, and Evan's blue analyses were all performed on the same day.

Comparison of soil extraction techniques. Spore extractions were conducted using a sucrose-based protocol, a reduced sucrose-based protocol, and a soil dilution method developed by our group. These protocols were compared by using subsamples of the same soil sample from the Muck Crops Research Station. There were three replications per protocol and the experiment was repeated.

In the sucrose-based protocol (Dhingra and Sinclair 1995), $25 \mathrm{~g}$ of dry soil was added to $100 \mathrm{ml}$ of $2 \%$ sodium hexametaphosphate (Sigma-Aldrich Co.), and the suspension was stirred for $1 \mathrm{~min}$ and allowed to settle overnight at room temperature. The suspension was then filtered through eight layers of cheesecloth and centrifuged at $1,000 \times g$ for $10 \mathrm{~min}$. The pellet was resuspended in water and spun at $1,000 \times g$ for $10 \mathrm{~min}$ two more times. The pellet was resuspended in $40 \%$ sucrose solution and this suspension was allowed to settle for 2 days at $4{ }^{\circ} \mathrm{C}$. The supernatant was decanted and diluted with an equal volume of $\mathrm{sdH}_{2} \mathrm{O}$. The resulting suspension was then centrifuged at $1,000 \times g$ for $1 \mathrm{~h}$, followed by resuspension of the pellet in a final volume of $5 \mathrm{ml}$ of $\mathrm{sdH}_{2} \mathrm{O}$.

In the reduced sucrose protocol (Hwang et al. 2015), $500 \mathrm{mg}$ of soil was mixed with $20 \mathrm{ml}$ of $\mathrm{sdH}_{2} \mathrm{O}$ in a blender for $1 \mathrm{~min}$. This suspension was filtered through eight layers of cheesecloth and spun at $3,900 \times g$ for $15 \mathrm{~min}$, and the supernatant was discarded. The pellet was resuspended in $5 \mathrm{ml}$ of $40 \%$ sucrose and vortexed for $2 \mathrm{~min}$. This suspension was spun at $1,700 \times g$ for $5 \mathrm{~min}$, followed by dilution of 
the supernatant with $45 \mathrm{ml}$ of $\mathrm{sdH}_{2} \mathrm{O}$. This suspension was spun at $3,900 \times g$ for $15 \mathrm{~min}$ and the supernatant was discarded. The pellet was resuspended in a final volume of $5 \mathrm{ml}$ of $\mathrm{sdH}_{2} \mathrm{O}$.

The soil dilution protocol developed in our lab was based on the protocol used to extract spores from clubs (Strelkov et al. 2007b). An electric blender was used to mix $3 \mathrm{~g}$ of soil in $100 \mathrm{ml}$ of $\mathrm{sdH}_{2} \mathrm{O}$ for $2 \mathrm{~min}$, followed by filtration through eight layers of cheesecloth. The soil extract was diluted 10-fold prior to resting spore quantification using a hemocytometer, unlike the other soil extracts, which were analyzed without dilution.

Statistical analysis. The data were analyzed as factorial experiments with two factors (PMA concentration and heat exposure) using analysis of variance in Statistix 10 (Analytical Software). In the studies of PMA concentration-heat exposure, Dunnett's test, which assesses the difference between a control and treatments, was used to compare the qPCR control and the $0 \mu \mathrm{M}$ PMA-PCR control versus the PMA treatments. Single-degree-of-freedom (df) contrasts within analysis of variance were used to assess differences among the control treatments, as well as linear and quadratic responses to PMA concentration. Regression was used to quantify the response to PMA concentration when it was identified as significant via contrasts. Mean separation was conducted using Tukey's honestly significant difference test at $P<0.05$. All spore estimates were log transformed prior to analysis but the nontransformed data are presented.

\section{Results}

Interaction of PMA and heat treatments. Mature resting spores only $\left(8 \times 10^{5}\right.$ spores $\left.\mathrm{ml}^{-1}\right)$, large volume. There was no difference in estimates of resting spore concentrations between the two controls: qPCR $\left(1.2 \times 10^{6} \pm 2.5 \times 10^{5}\right.$ spores $\left.\mathrm{ml}^{-1}\right)$ and $0 \mu \mathrm{M}$ PMA-PCR $\left(1.0 \times 10^{6} \pm 3.4 \times 10^{5}\right.$ spores $\left.\mathrm{ml}^{-1}\right)$. Also, there was no difference between the estimates of spore concentration of non-heat-treated samples for 0 compared with 40, 80, and $120 \mu \mathrm{M}$ PMA-PCR, according to Dunnett's test (Fig. 1). In contrast, estimates of the concentrations of heat-treated spores were substantially lower, following addition of PMA (Fig. 1). Based on these results, the controls (qPCR and $0 \mu \mathrm{M}$ PMA-PCR) were dropped from subsequent analyses to focus on the PMA assessments.

Analysis of the 40, 80, and $120 \mu \mathrm{M}$ PMA-PCR data alone identified a main effect of heat treatment $(P=0.0001)$ but no PMA effect or heat-PMA interaction. The spore concentration after 0 and $30 \mathrm{~min}$ heat treatment was similar but the concentration after $60 \mathrm{~min}$ of heat

\section{Mature spores, large volume}

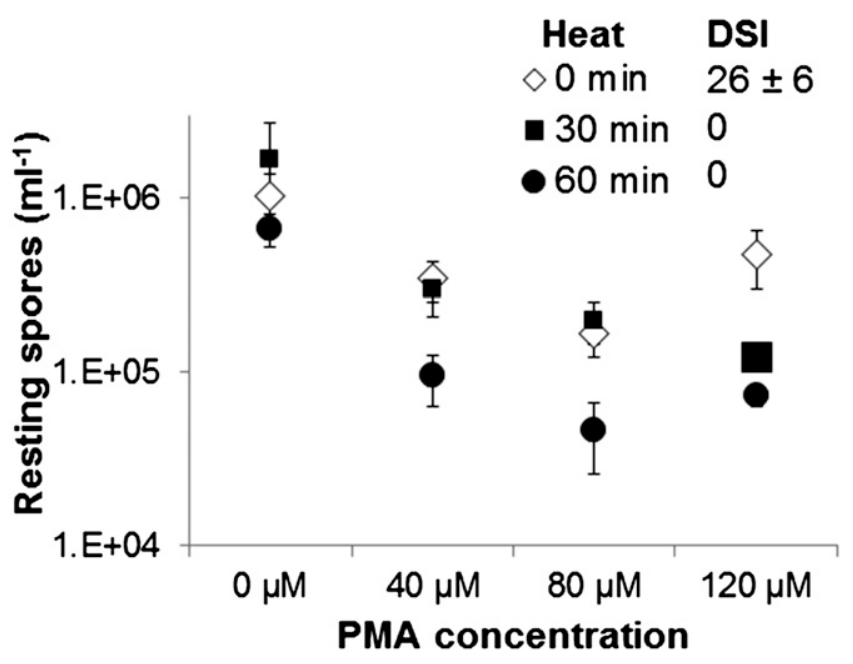

Fig. 1. Effect of duration of exposure to $80^{\circ} \mathrm{C}$ and propidium monoazide (PMA) concentration on quantitative polymerase chain reaction estimates of large volumes of mature resting spores of Plasmodiophora brassicae, on a logarithmic scale. Capped lines represent standard error (SE). Average disease severity index (DSI \pm $\mathrm{SE})$ ratings at 6 weeks post-inoculation of clubroot-susceptible Brassica napus plants inoculated with each spore suspension are also presented. was reduced by $85 \%$ relative to the non-heat-treated control (Fig. 1). The absence of a PMA effect indicated that PMA concentration did not influence the estimate of spore concentration in this experiment.

Immature resting spores $\left(5 \times 10^{7}\right.$ resting spores $\left.\mathrm{ml}^{-1}\right)$, small volume. Similar to the mature resting spores, there was no difference between the two controls (qPCR and $0 \mu \mathrm{M}$ PMA) in estimates of the concentration of immature spores based on single-df contrasts. Dunnett's test showed that estimates of the concentration of immature spores were reduced by $>90 \%$ by addition of PMA relative to the $0 \mu \mathrm{M}$ PMA-PCR control (Fig. 2). Therefore, these controls were also dropped from subsequent analyses.

Analysis of PMA concentration $(40,80$, and $120 \mu \mathrm{M})$ showed that there was an effect of heat treatment $(P<0.0001)$ and a PMA effect $(P=0.008)$ but no heat-PMA interaction. Estimates of resting spore concentration decreased with increasing duration of heat exposure $(P<0.05)$, and decreased linearly as PMA concentration increased $(P=0.004)$. There was no relationship between PMA concentration and spore estimates for the 0 - and 5-min heat treatments. However, estimates of spore concentration declined with increasing concentration of PMA when spores were heat treated for $10 \mathrm{~min}$ (log of spore concentration $=5.44-9.99 \times 10^{-3} \mathrm{PMA}$ concentration; $R^{2}=0.83$, $P=0.0006)$ (Fig. 2).

Mature and immature spores $\left(8 \times 10^{6}\right.$ spores $\left.\mathrm{ml}^{-1}\right)$, large volume. As in the previous experiments, estimates from the qPCR control did not differ from the $0 \mu \mathrm{M}$ PMA-PCR, regardless of heat treatment (data not shown). For mature spores that had not been heat treated, Dunnett's test indicated that there was no difference between spore concentration in the control ( $0 \mu \mathrm{M}$ PMA) versus the PMA treatments (Fig. 3A). In contrast, when PMA was added to heat-treated resting spores, estimates of mature spores were lower relative to the $0 \mu \mathrm{M}$ PMA control. For immature spores, the PMA treatments did not affect estimates of heat-treated spore concentration relative to the $0 \mu \mathrm{M}$ PMA control, based on Dunnett's test (Fig. 3B). However, estimates of non-heat-treated immature spore concentration in the $120 \mu \mathrm{M}$ PMA treatment were $74 \%$ lower than the $0 \mu \mathrm{M}$ PMA control. To be consistent with assessment of the previous experiment, the estimates from $\mathrm{qPCR}$ and $0 \mu \mathrm{M}$ PMA-PCR were excluded from further analyses.

When only 40, 80, and $120 \mu \mathrm{M}$ PMA-PCR estimates were analyzed, there were differences in the response of immature and mature resting spores (Fig. 3). For mature spores, the effects of PMA $(P=$ $0.0001)$, heat treatment $(P<0.0001)$, and PMA $\times$ heat $(P=0.006)$ were significant. As in the previous experiment, estimates of spore concentration were substantially reduced after $60 \mathrm{~min}$ of heat treatment

\section{Immature spores, small volume}

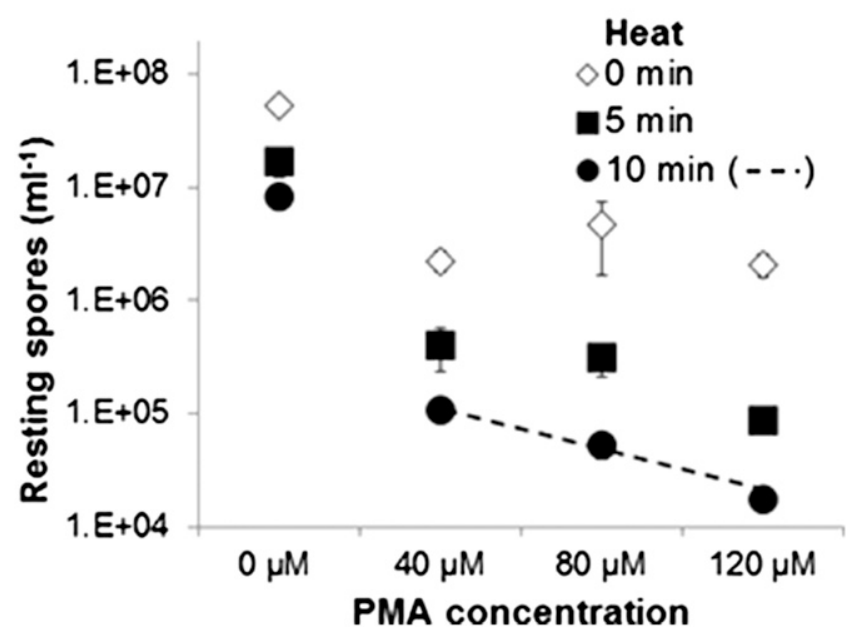

Fig. 2. Effect of duration of exposure to $80^{\circ} \mathrm{C}$ and propidium monoazide (PMA) concentration on quantitative polymerase chain reaction estimates of small volumes of immature resting spores of Plasmodiophora brassicae. Capped lines indicate standard error. Only regression lines of PMA concentration significant at $P<0.05$ are shown. 
compared with the 0 - or 30-min treatments (Fig. 3A). PMA concentration had no impact on non-heat-treated spores but estimates of spore concentration declined slightly with increased PMA concentration following heat treatment for $30 \mathrm{~min}(\log$ [spores] $=6.98-$ $5.56 \times 10^{-3}$ PMA concentration; $\left.R^{2}=0.63, P=0.01\right)$ and declined substantially following heat treatment for $60 \mathrm{~min}$ (log [spores] $=$ $6.40-8.63 \times 10^{-3}$ PMA concentration; $\left.R^{2}=0.47, P=0.04\right)$. PMA-PCR estimates of spore concentration for mature spores were about $90 \%$ lower after heat treatment for 60 min compared with the non-heat-treated control (Fig. 3A).

For immature spores, the effects of PMA $(P=0.004)$ and heat treatment $(P=0.0005)$ were significant but there was no PMA-heat interaction. Overall, estimates of spore concentration were lower in the 60-min heat treatment than the 0- or 30-min treatments but there were no differences between heat treatments at each PMA concentration. Estimates of spore concentration were reduced with increasing concentration of PMA when the spore suspension was not exposed to heat $(0$ min treatment $)(\log$ [spores] $=6.10+0.020$ PMA concentration $-1.56 \times 10^{-4}$ PMA concentration $\left.{ }^{2} ; R^{2}=0.86, P=0.003\right)$ but there was no relationship between the 30 - and 60 -min heat treatments and PMA concentration (Fig. 3B).

Mature $\left(4.4 \times 10^{10}\right.$ spores $\left.\mathrm{ml}^{-1}\right)$ and immature spores $\left(4.6 \times 10^{9}\right.$ spores $\left.\mathrm{ml}^{-1}\right)$, small volume. As in the previous experiments, estimates of the concentration of mature spores that were not exposed to heat $(0 \mathrm{~min}$ of heat $)$ did not differ between 0 and $80 \mu \mathrm{M}$ PMAPCR. In contrast, treatment of immature resting spores with $80 \mu \mathrm{M}$ PMA reduced estimates of spore concentration by $85 \%$ compared with $0 \mu \mathrm{M}$ PMA-PCR. Heat treatment and treatment with $80 \mu \mathrm{M}$ PMA-PCR resulted in a decrease in the estimates of spore concentration of $90 \%$ for immature and $99 \%$ for mature spores, relative to nontreated samples (Table 1).

A

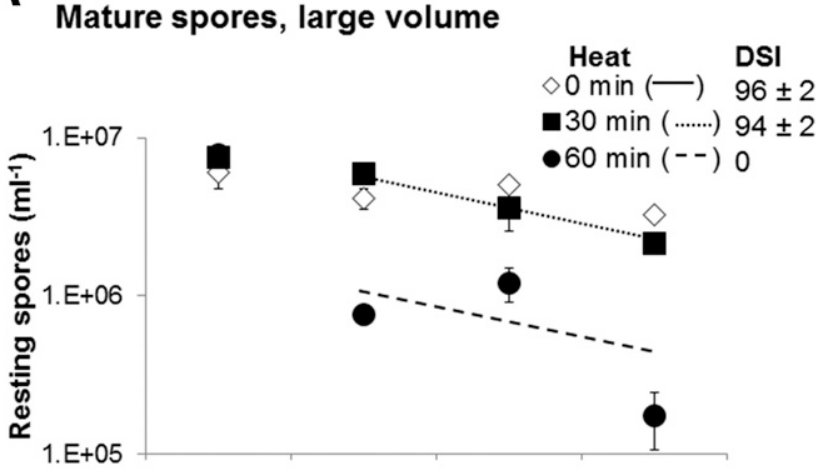

B

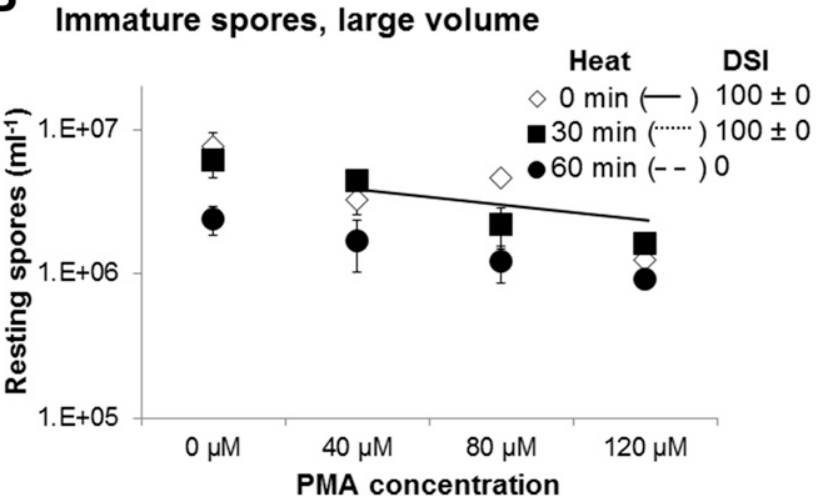

Fig. 3. Effect of duration of exposure to $80^{\circ} \mathrm{C}$ and propidium monoazide (PMA) concentration on quantitative polymerase chain reaction estimates of large volumes of $\mathbf{A}$, mature and $\mathbf{B}$, immature resting spores of Plasmodiophora brassicae, on a logarithmic scale. Capped lines indicate standard error (SE). Only regression lines of PMA concentration significant at $P<0.05$ are shown. Average disease severity index (DSI $\pm \mathrm{SE}$ ) ratings at 6 weeks post-inoculation of clubroot-susceptible Brassica napus plants inoculated with each spore suspension are also presented.
Bioassays. For the experiment that examined large volumes of mature resting spores only, susceptible canola seedlings were inoculated with a low concentration $\left(5 \mathrm{ml}\right.$ of $8 \times 10^{5}$ spores $\mathrm{ml}^{-1}$ ) of resting spores. Plants inoculated with non-heat-treated spores developed moderate levels of clubroot but no clubroot developed on plants inoculated with heat-treated spores (Fig. 1).

In the bioassays of non-heat-treated mature and immature spores ( $5 \mathrm{ml}$ of $1 \times 10^{6}$ spores $\mathrm{ml}^{-1}$ ), inoculation with mature spores resulted in severe clubroot symptoms in both the experiment with replicates $(\mathrm{CI}=100 \pm 0 \%, \mathrm{DSI}=89 \pm 4)$ and the experiment without replicates $(\mathrm{CI}=100 \%$, DSI $=100)$ but inoculation with immature spores produced few clubroot symptoms in the experiment with replicates $(\mathrm{CI}=11 \pm 7 \%$, DSI $=4 \pm 2)$ and no clubroot symptoms in the experiment without replicates. In the large-volume PMA-PCR experiment that compared non-heat-treated and heat-treated mature and immature spores, seedlings were inoculated with a higher concentration of resting spores $\left(5 \mathrm{ml}\right.$ of $8 \times 10^{6}$ spores $\left.\mathrm{ml}^{-1}\right)$. Inoculation with non-heat-treated spores resulted in severe clubroot. Inoculation with resting spores that were heat treated for $30 \mathrm{~min}$ also produced high levels of clubroot from both mature and immature spores but heat treatment for $60 \mathrm{~min}$ reduced clubroot incidence and severity to zero for both mature and immature resting spores (Fig. 3).

Staining with Evan's blue. The viability of resting spores assessed in the bioassay of immature and mature spores was also assessed using a vital stain, Evan's blue. There were no differences in the proportion of viable (nonstaining) spores among the treatments (mean $89 \%$, data not shown).

Comparison of soil extraction techniques. Differences were found in the efficacy of the extraction protocols for extracting $P$. brassicae resting spores from muck soil. qPCR estimates of spore concentration for the PowerSoil DNA extraction kit and the soil dilution protocol were more than 200-fold higher than the sucrosebased extraction methods (Fig. 4). Estimates from direct spore counts showed a similar trend; highest from the soil dilution method, lower from the reduced sucrose method, and lowest from the sucrose method (Fig. 4). Spore counts were not available for the PowerSoil method because it was performed directly on soil samples without any spore extraction.

\section{Discussion}

This is the first report describing the use of PMA-PCR to assess the viability of resting spores of $P$. brassicae. In this analysis, viable, mature spores (defined as spores capable of initiating infection and subsequent development of clubroot symptoms) were amplified and assessed directly, and the proportion of nonviable or immature spores (too immature or deteriorated to produce clubroot symptoms) was calculated as the difference between estimates from qPCR (which quantifies viable, mature plus nonviable or immature spores) and PMA-PCR (which quantifies viable, mature spores). The PMA treatment protocol was quick and easy to perform prior to qPCR analysis, and PMA-PCR provided an improved estimate of the effective inoculum concentration of $P$. brassicae compared with qPCR.

Bioassays demonstrated that severe clubroot symptoms consistently developed following inoculation with mature spores (collected

Table 1. Effect of exposure of small volumes of resting spore suspensions to high temperature $\left(80^{\circ} \mathrm{C}\right.$ for $\left.10 \mathrm{~min}\right)$ and propidium monoazide (PMA) pretreatment on quantitative polymerase chain reaction estimates of the concentration of resting spores of Plasmodiophora brassicae $\left(\times 10^{8}\right.$ spores $\left.\mathrm{ml}^{-1}\right)$ from immature and mature clubs ${ }^{\mathrm{z}}$

\begin{tabular}{lcc}
\hline & \multicolumn{2}{c}{$\begin{array}{c}\text { Spores }\left(\times \mathbf{1 0}^{\mathbf{8}} \text { spores } \mathbf{~ m l}^{\mathbf{- 1}} \pm\right. \\
\text { standard error })\end{array}$} \\
\cline { 2 - 3 } Heat and PMA treatments & Immature & Mature \\
\hline 0 min at $80^{\circ} \mathrm{C}+0 \mu \mathrm{M}$ PMA & $46 \pm 11 \mathrm{a}$ & $440 \pm 240 \mathrm{a}$ \\
0 min at $80^{\circ} \mathrm{C}+80 \mu \mathrm{M}$ PMA & $7 \pm 0.6 \mathrm{~b}$ & $160 \pm 76 \mathrm{a}$ \\
10 min at $80^{\circ} \mathrm{C}+80 \mu \mathrm{M}$ PMA & $0.7 \pm 0.08 \mathrm{c}$ & $1.6 \pm 0.05 \mathrm{~b}$ \\
\hline
\end{tabular}

${ }^{\mathrm{z}}$ Means in a column followed by the same letter do not differ based on Tukey's test at $P<0.05$. 
from mature clubs at approximately 9 weeks after seeding) that had not been exposed to a heat treatment ( 0 -min control). This demonstrated that the mature spores were initially viable. However, inoculation with heat-treated spores resulted in reduced or no clubroot symptoms, indicating that many of the spores were no longer viable (Figs. 1 and 3A). Experiments conducted with large volumes of mature resting spores demonstrated that, at a moderate spore concentration, PMA-PCR did not affect estimates of the concentration of non-heat-treated spores but yielded lower estimates of spore concentration from heat-treated spores (Fig. 1). PMA-PCR also differentiated between a high concentration of mature spores that were heat treated for a short duration (produced high levels of clubroot in the bioassay) compared with spores that were heat treated for longer, which did not produce clubroot symptoms in a bioassay (Fig. 3A). This showed that PMA-PCR could differentiate between viable and nonviable resting spores.

In the bioassays of mature versus immature resting spores (collected at 6 weeks after seeding), inoculation with a moderate concentration of immature spores resulted in lower clubroot incidence and severity than a similar concentration of mature spores. However, inoculation with a high concentration of immature spores produced high levels of clubroot symptoms (Fig. 3B). This indicated that many of the spores in the immature collection were not capable of causing infection but that, when inoculated at a high concentration, the immature collection of spores contained enough viable spores to reach the minimum threshold needed for clubroot infection and development.

PMA-PCR assessments were less consistent with immature spores than with mature spores. In the experiment using small volumes of immature spores only, addition of PMA resulted in a significant and substantial reduction in estimates of resting spore concentration (Fig. 2). However, the reduction was smaller in the large-volume experiment (Fig. 3B) and in the experiment that assessed both mature and immature spores in small volumes (Table 1). Also, PMA-PCR differentiated between non-heat-treated and heat-treated immature resting spores in one experiment (Fig. 2) but not in another (Fig. 3B).

Three PMA concentrations $(40,80$, and $120 \mu \mathrm{M})$ were assessed to determine the optimal concentration for use with resting spore suspensions of $P$. brassicae. Increasing the concentration of PMA did not always affect the estimates of mature spores in the sample but

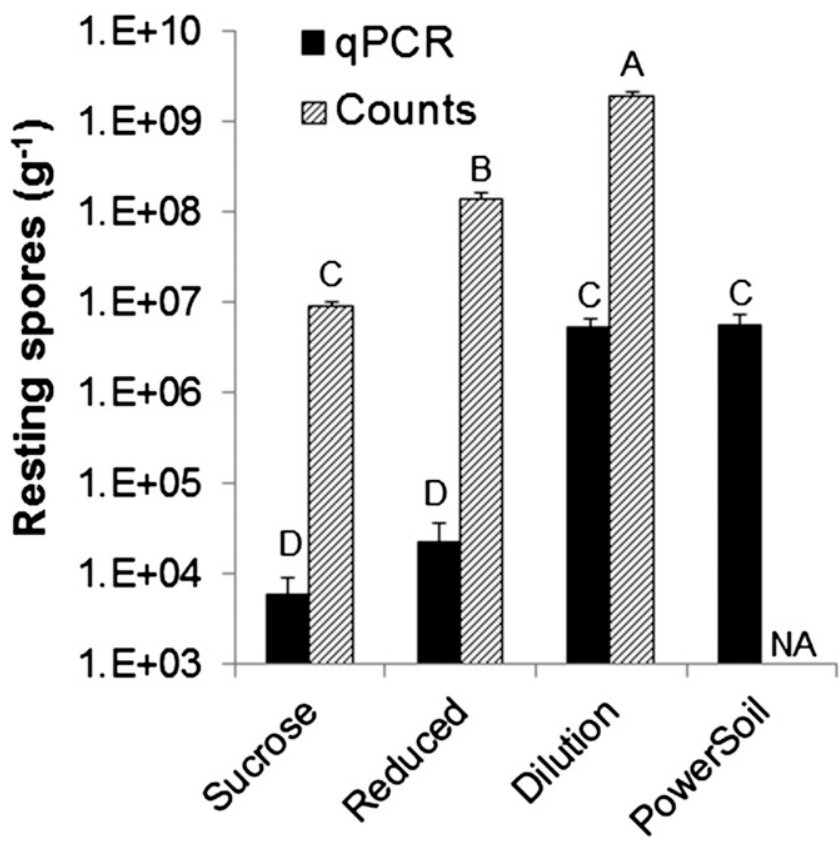

Fig. 4. Concentration of resting spores of Plasmodiophora brassicae in naturally infested muck soil extracted using four protocols and estimated using direct spore counts or quantitative polymerase chain reaction (qPCR), on a logarithmic scale. Means followed by the same letter do not differ based on Tukey's test at $P<0.05$. Capped lines represent standard error. NA = not applicable. estimates of spore concentration were reduced at high concentrations of PMA in several treatments. These studies indicated that the optimal PMA concentration is dependent on the concentration of nonviable resting spores in the sample. For example, all three PMA concentrations provided the same estimates of spore concentration from a moderate concentration $\left(8 \times 10^{5}\right.$ spores $\left.\mathrm{ml}^{-1}\right)$ of mature resting spores in the large-volume mature resting spore study (Fig. 1). This indicates that the system was saturated with PMA at $40 \mu \mathrm{M}$. However, saturation may not have been achieved in the assessment of a high concentration $\left(8 \times 10^{6}\right.$ spores $\left.\mathrm{ml}^{-1}\right)$ of mature resting spores in the large-volume mature versus immature study, where the estimated number of spores decreased with increased PMA concentration (Fig. 3A). This indicated that a range of PMA concentrations around $120 \mu \mathrm{M}$ should be tested to confirm that saturation is reached before analyzing multiple samples. Although PMA saturation of the resting spore suspensions may not always have been achieved in the current studies, results using 80 and $120 \mu$ M PMA-PCR were consistent with the bioassays.

How PMA-PCR differentiates between mature and immature spores is not known. Resting spores possess a cell wall composed of four layers of protein and chitin surrounding a cell membrane (Buczacki and Moxham 1983; Moxham and Buczacki 1983). Scanning electron microscopy demonstrated that mature resting spores have a thinner outer layer and more visible spines than immature resting spores (Ikegami et al. 1978; Kageyama and Asano 2009). The structural differences between mature and immature resting spores may result in immature spores being more permeable to PMA before heat treatment and less permeable to PMA after heat treatment. This hypothesis is supported by a study of resting spores treated at $100^{\circ} \mathrm{C}$ for $10 \mathrm{~min}$, in which the outermost fibers were removed but the remaining layers were unaffected (Buczacki and Moxham 1983). Given that mature resting spores have a thinner outer layer than immature spores, mature spores may be more sensitive to extreme heat than immature spores.

Staining with Evan's blue did not distinguish between heat-treated and non-heat-treated spores, or between mature and immature resting spores. The molecular weight of PMA (511) is substantially smaller than Evan's blue (961). This could make PMA a more reliable indicator of viability in this system because it could move more readily through the membranes of nonviable resting spores.

We believe that the heat treatments in this study reduced resting spore viability rather than simply inhibiting germination. However, it is not possible to differentiate microscopically between a spore that is not viable and one that does not germinate. In a previous study, Evan's blue did not differentiate between resting spores of $P$. brassicae treated with the fungicide flusulfamide, which did not cause clubroot, and the nontreated control, which caused clubroot. The authors concluded that flusulfamide inhibited germination of resting spores instead of rendering them nonviable (Tanaka et al. 1999). Viability of resting spores can be determined by monitoring the incorporation of ${ }^{14} \mathrm{C}$-labeled nutrients into their protein and lipid profile (Keen et al. 1969); however, that was beyond the scope of the current study. Therefore, the possibility that most of the spores analyzed in this study were viable, as indicated by the Evan's blue analysis, cannot be completely excluded.

Other studies have investigated methods to identify viable resting spores of $P$. brassicae. Two fluorochromes (calcofluor white M2R and ethidium bromide) were used to distinguish between non-heattreated and heat-treated suspensions of $P$. brassicae resting spores. The results were correlated with viability as indicated by clubroot bioassays (Takahashi and Yamaguchi 1988, 1989). However, when resting spores were exposed to a wide array of treatments, including physical (e.g., heat), ionic (e.g., pH), and chemical (e.g., bleach) treatments, the results were not consistent with bioassays (Donald et al. 2002). Whether estimates from PMA-PCR are consistent with bioassays after resting spores are exposed to other treatments has not yet been assessed.

Three protocols for extracting $P$. brassicae resting spores from soil were compared with the PowerSoil DNA extraction kit: (i) a sucrose-based protocol (Dhingra and Sinclair 1995), (ii) a reduced-sucrose-based protocol 
(Hwang et al. 2015), and (iii) a simple soil dilution protocol. The soil dilution technique extracted the most resting spores. The visual counts of resting spores were consistently higher than the qPCR estimates for each of the methods. The visual counts could have been overestimated from inclusion of empty resting spores, with no DNA after germination.

The current study demonstrated that PMA-PCR can be used to quantify viable and mature resting spores of $P$. brassicae. The bioassays demonstrated that prolonged heat treatment reduced the viability of resting spores, based on reduced clubroot symptom development. qPCR did not detect any reduction in spore numbers following heat treatment because it amplified DNA from both viable and nonviable spores. Estimates of spore concentration from PMA-PCR following heat treatment were substantially reduced relative to the non-heattreated control, which indicated that pretreatment with PMA reduced or eliminated amplification of the DNA from heat-damaged spores. The response to PMA was more consistent in mature resting spores than in immature collections of spores. However, immature spores would generally make up only a tiny proportion of the resting spore population in naturally infested fields.

PMA-PCR assessment could be used as a routine confirmation of the quality of inoculum for inoculation studies, which would represent a substantial improvement over visual counts of spore concentration. PMA-PCR can also be used to provide estimates of resting spore viability wherever resource-intensive bioassays have previously been used, and to assess the effects of chemical or cultural methods on populations of resting spores of $P$. brassicae in soil.

\section{Acknowledgments}

We thank J. Dalton for providing mature clubs, S. Vail for providing seed of ACS-N39, and the staff at the Muck Crops Research Station for help and advice. Funding for the study was provided by Sask Canola, the Western Grains Research Fund, the Agriculture Development Fund of Saskatchewan, and the Canola Council of Canada and Agriculture and Agri-Food Canada as part of the Canola Science Cluster of Growing Forward 2.

\section{Literature Cited}

Agustí, G., Fittipaldi, M., Morato, J., and Codony, F. 2013. Viable quantitative PCR for assessing the response of Candida albicans to antifungal treatment. Appl. Microbiol. Biotechnol. 97:341-349.

Ahmed, H. U., Hwang, S. F., Strelkov, S. E., Gossen, B. D., Peng, G., Howard, R. J., and Turnbull, G. D. 2011. Assessment of bait crops to reduce inoculum of clubroot (Plasmodiophora brassicae) of canola. Can. J. Plant Sci. 91:545-551.

Ando, S., Yamada, T., Asano, T., Kamachi, S., Tsushima, S., Hagio, T., and Tabei, Y. 2006. Molecular cloning of PbSTKL1 gene from Plasmodiophora brassicae expressed during clubroot development. J. Phytopathol. 154:185-189.

Andorrà, I., Esteve-Zarzoso, B., Guillamon, J. M., and Mas, A. 2010. Determination of viable wine yeast using DNA binding dyes and quantitative PCR. Int. J. Food Microbiol. 144:257-262.

Bilodeau, G. J. 2011. Quantitative polymerase chain reaction for the detection of organisms in soil. CAB Rev. Perspect. Agric. Vet. Sci. Nutr. Nat. Resour. 6:1-14.

Buczacki, S. T., and Moxham, S. E. 1983. Structure of the resting spore wall of Plasmodiophora brassicae revealed by electron microscopy and chemical digestion. Trans. Br. Mycol. Soc. 81:221-231

Crête, R., Laliberté, J., and Jasmin, J. J. 1963. Lutte chimique contre la hernie, Plasmodiophora brassicae Wor., des cruciferes en sols mineral et organique. Can. J. Plant Sci. 43:349-354.

Deora, A., Gossen, B. D., Amirsadeghi, S., and McDonald, M. R. 2015. A multiplex qPCR assay for detection and quantification of Plasmodiophora brassicae in soil. Plant Dis. 99:1002-1009.

Dhingra, O. D., and Sinclair, J. B. 1995. Basic Plant Pathology Methods, 2nd ed. CRC Press, Boca Raton, FL.

Dixon, G. R. 2009. The occurrence and economical impact of Plasmodiophora brassicae and clubroot disease. J. Plant Growth Regul. 28:194-202.

Donald, E. C., Lawrence, J. M., and Porter, I. J. 2002. Evaluation of a fluorescent staining technique as an indicator of pathogenicity of resting spores of Plasmodiophora brassicae. Australas. Plant Pathol. 31:373-379.

Feng, J., Hwang, R. U., Hwang, S.-F., Strelkov, S. E., Gossen, B. D., Zhou, Q.-X., and Peng, G. 2010. Molecular characterization of a serine protease Pro1 from Plasmodiophora brassicae that stimulates resting spore germination. Mol. Plant Pathol. 11:503-512.
Fittipaldi, M., Nocker, A., and Codony, F. 2012. Progress in understanding preferential detection of live cells using viability dyes in combination with DNA amplification. J. Microbiol. Methods 91:276-289.

Gossen, B. D., McDonald, M. R., Hwang, S. F., Strelkov, S. E., and Peng, G. 2013 A comparison of clubroot development and management on canola and Brassica vegetables. Can. J. Plant Pathol. 35:175-191.

Hwang, S. F., Ahmed, H. U., Strelkov, S. E., Gossen, B. D., Turnbull, G. D., Peng, G., and Howard, R. J. 2011. Seedling age and inoculum density affect clubroot severity and seed yield in canola. Can. J. Plant Sci. 91:183-190.

Hwang, S. F., Ahmed, H. U., Zhou, Q., Turnbull, G. D., Strelkov, S. E., Gossen, B. D., and Peng, G. 2015. Effect of host and non-host crops on Plasmodiophora brassicae resting spore concentrations and clubroot of canola. Plant Pathol. 64: 1198-1206

Hwang, S. F., Howard, R. J., Strelkov, S. E., Gossen, B. D., and Peng, G. 2014 Management of clubroot (Plasmodiophora brassicae) on canola (Brassica napus) in western Canada. Can. J. Plant Pathol. 36 (S1):49-65.

Ikegami, H., Mukobata, H., and Naiki, T. 1978. Scanning electron microscopy of Plasmodiophora brassicae in diseased root cells of turnip and Chinese cabbage studies on the clubroot of cruciferous plant part 3. Ann. Phytopathol. Soc. Jpn. 44:456-464.

Ingram, D. S., and Tommerup, I. C. 1972. The life history of Plasmodiophora brassicae Woron. Proc. R. Soc. London Ser. B. Biol. Sci. 180:103-112.

Kageyama, K., and Asano, T. 2009. Life cycle of Plasmodiophora brassicae. J. Plant Growth Regul. 28:203-211.

Keen, N. T., Reddy, M. N., and Williams, P. H. 1969. Isolation and properties of Plasmodiophora brassicae plasmodia from infected crucifer tissues and from tissue culture callus. Phytopathology 59:637-644.

Moxham, S. E., and Buczacki, S. T. 1983. Chemical composition of the resting spore wall of Plasmodiophora brassicae. Trans. Br. Mycol. Soc. 80:297-304.

Moyne, A.-L., Harris, L. J., and Marco, M. L. 2013. Assessments of total and viable Escherichia coli $\mathrm{O} 157: \mathrm{H} 7$ on field and laboratory grown lettuce. PLoS One 8:e70643.

Peng, G., Pageau, D., Strelkov, S. E., Gossen, B. D., Hwang, S. F., and Lahlali, R. 2015. A >2-year crop rotation reduces resting spores of Plasmodiophora brassicae in soil and the impact of clubroot on canola. Eur. J. Agron. 70:78-84.

Peng, G., Lahlali, R., Hynes, R. H., Gossen, B. D., Falk, F. C., Yu, F., Boyetchko, S. M., McGregor, L., Pageau, D., Anderson, K., Hwang, S. F., Strelkov, S. E., McDonald, M. R., and Turkington, T. K. 2013. Assessment of crop rotation, cultivar resistance and Bacillus subtilis biofungicide for control of clubroot on canola. Acta Hortic. 1005:591-598.

Rawsthorne, H., Dock, C. N., and Jaykus, L. A. 2009. PCR-based method using propidium monoazide to distinguish viable from nonviable Bacillus subtilis spores. Appl. Environ. Microbiol. 75:2936-2939.

Rennie, D. C., Manolii, V. P., Cao, T., Hwang, S. F., Howard, R. J., and Strelkov, S. E. 2011. Direct evidence of surface infestation of seed and tubers by Plasmodiophora brassicae and quantification of spore loads. Plant Pathol. 60:811-819.

Siemens, J., Graf, H., Bulman, S., In, O., and Ludwig-Müller, J. 2009. Monitoring expression of selected Plasmodiophora brassicae genes during clubroot development in Arabidopsis thaliana. Plant Pathol. 58:130-136.

Strelkov, S. E., Manolii, V. P., Cao, T., Hwang, S. F., and Orchard, D. 2007a. Incidence of clubroot on canola in Alberta in 2006. Can. Plant Dis. Surv. 87:109-111.

Strelkov, S. E., Manolii, V. P., Cao, T., Xue, S., and Hwang, S. F. 2007b. Pathotype classification of Plasmodiophora brassicae and its occurrence in Brassica napus in Alberta, Canada. J. Phytopathol. 155:706-712.

Strelkov, S. E., Tewari, J. P., and Smith-Degenhardt, E. 2006. Characterization of Plasmodiophora brassicae populations from Alberta, Canada. Can. J. Plant Pathol. 28:467-474.

Takahashi, K., and Yamaguchi, T. 1988. A method for assessing the pathogenic activity of resting spores of Plasmodiophora brassicae by fluorescence microscopy. Ann. Phytopathol. Soc. Jpn. 54:466-475.

Takahashi, K., and Yamaguchi, T. 1989. Assessment of pathogenicity of resting spores of Plasmodiophora brassicae in soil by fluorescence microscopy. Ann. Phytopathol. Soc. Jpn. 55:621-628.

Tanaka, S., Kochi, S.-I., Kunita, H., Ito, S.-I., and Kameya-Iwaki, M. 1999 Biological mode of action of the fungicide, flusulfamide, against Plasmodiophora brassicae (clubroot). Eur. J. Plant Pathol. 105:577-584

Vesper, S., McKinstry, C., Hartmann, C., Neace, M., Yoder, S., and Vesper, A 2008. Quantifying fungal viability in air and water samples using quantitative PCR after treatment with propidium monoazide (PMA). J. Microbiol. Methods 72:180-184.

Wang, H., Gill, C. O., and Yang, X. 2014. Development of a real-time PCR procedure for quantification of viable Escherichia coli in populations of $E$. coli exposed to lactic acid, and the acid tolerance of verotoxigenic $E$. coli (VTEC) from cattle hides. Food Control 43:104-109.

Wu, L.-Y., Siemens, J., Li, S.-K., Ludwig-Müller, J., Gong, Y.-J., Zhong, L., and He, J.-M. 2012. Estimating Plasmodiophora brassicae gene expression in lines of B. rapa by RT-PCR. Sci. Hortic. (Amsterdam) 133:1-5. 